\title{
Depression, Anxiety, and Social Environmental Adversity as Potential Modulators of the Immune Tumor Microenvironment in Breast Cancer Patients
}

\author{
Eida M. Castro-Figueroa ${ }^{1,2, *}$, Karina I. Acevedo ${ }^{1}$, Cristina I. Peña-Vargas ${ }^{1,2}\left(\right.$, Normarie Torres-Blasco ${ }^{1,2}$, \\ Idhaliz Flores ${ }^{3,4}$, Claudia B. Colón-Echevarria ${ }^{5}$ (i), Lizette Maldonado ${ }^{6}$, Zindie Rodríguez ${ }^{6}$, \\ Alexandra N. Aquino-Acevedo ${ }^{5}$, Heather Jim ${ }^{7}\left(\mathbb{0}\right.$, María I. Lazaro ${ }^{1}$ and Guillermo N. Armaiz-Peña $3,5,6 \oplus$
}

1 Clinical Psychology Program, School of Behavioral and Brain Sciences, Ponce Health Sciences University, Ponce, PR 00716, USA; kacevedo15@stu.psm.edu (K.I.A.); cpena@psm.edu (C.I.P.-V.); normarietorres@psm.edu (N.T.-B.); mlazaro17@stu.psm.edu (M.I.L.)

2 Division of Mental Health, Ponce Research Institute, Ponce, PR 00716, USA

3 Division of Women's Health, Ponce Research Institute, Ponce, PR 00716, USA; iflores@psm.edu (I.F.); garmaiz@psm.edu (G.N.A.-P.)

4 Division of Microbiology, Department of Basic Sciences, School of Medicine, Ponce Health Sciences University, Ponce, PR 00716, USA

check for
updates

Citation: Castro-Figueroa, E.M.; Acevedo, K.I.; Peña-Vargas, C.I.; Torres-Blasco, N.; Flores, I.;

Colón-Echevarria, C.B.; Maldonado, L.; Rodríguez, Z.; Aquino-Acevedo, A.N.; Jim, H.; et al. Depression, Anxiety, and Social Environmental Adversity as Potential Modulators of the Immune Tumor

Microenvironment in Breast Cancer Patients. Med. Sci. 2021, 9, 46. https://doi.org/10.3390/medsci 9020046

Academic Editor: Tracy

Murray-Stewart

Received: 23 April 2021

Accepted: 11 June 2021

Published: 21 June 2021

Publisher's Note: MDPI stays neutral with regard to jurisdictional claims in published maps and institutional affiliations.

\section{Copyright: (c) 2021 by the authors.} Licensee MDPI, Basel, Switzerland. This article is an open access article distributed under the terms and conditions of the Creative Commons Attribution (CC BY) license (https:/ / creativecommons.org/licenses/by/ $4.0 /)$.
5 Division of Pharmacology, Department of Basic Sciences, School of Medicine, Ponce Health Sciences University, Ponce, PR 00716, USA; ccolon13@stu.psm.edu (C.B.C.-E.); aaquino18@stu.psm.edu (A.N.A.-A.)

6 Division of Cancer Biology, Ponce Research Institute, Ponce, PR 00716, USA; lizettemaldonado@gmail.com (L.M.); zrodriguez@psm.edu (Z.R.)

7 Department of Health Outcomes and Behavior, H. Lee Moffitt Cancer Center and Research Institute, Tampa, FL 33612, USA; Heather.Jim@moffitt.org

* Correspondence: ecastro@psm.edu

\begin{abstract}
Background: Mounting data suggest that exposure to chronic stress is associated with worse breast cancer outcomes. This study aimed to explore the impact of social environmental adversity (SEA, e.g., child abuse, crime, sexual, and physical violence), depressive symptomatology, and anxiety on immune cell infiltration into the breast tumor microenvironment. Methods: Participants $(n=33)$ completed a series of surveys assessing depression and anxiety symptoms, adverse childhood events (ACE), and trauma history. Tumor-associated macrophages (CD68+), B cells (CD19+), and T cells $(\mathrm{CD} 3+)$ were identified by immunohistochemical analyses of formalin-fixed paraffin-embedded tumor samples and quantified. Spearman rank tests were used to explore the relationships between the variables studied. Results: Exposure to SEA was high (ACE $=72 \%$, exposure to crime $=47 \%$, and exposure to physical/sexual assault $=73 \%$ ) among participants. Moreover, $30 \%$ reported a comorbid history of depression and ACE; 39\% reported one or more traumatic events, and clinically significant depression symptomatology, while $21 \%$ reported trauma history and significant anxiety symptomatology. Increased tumor-infiltrating B cells were significantly correlated with exposure to crime, anxiety symptoms, and exposure to an ACE. The ACE plus anxiety group presented the highest infiltration of B cells, T cells, and macrophages. Conclusion: These findings support a role for SEA, anxiety symptoms, and depression as potential modulators of the immune tumor microenvironment in breast cancer.
\end{abstract}

Keywords: tumor microenvironment; breast cancer; depression; anxiety; immune cells; social environmental adversity

\section{Introduction}

Breast cancer is the most common cancer diagnosed in women, with an estimated 2.3 million new cases each year globally [1]. Worldwide, breast cancer is the fifth leading cause of cancer-related mortality and the leading cause of cancer-related deaths in most Latin American countries [1] including Puerto Rico (a USA territory with a large Hispanic 
population) [1,2]. Even though several known global health disparities drive systemic breast cancer inequities (e.g., access to care), little is known about the role of exposure to social environmental adversity in breast cancer on clinical outcomes. Of note, social environmental adversity (SEA) is a term used to group the exposure of lifetime traumatic experiences such as child abuse, physical and sexual abuse, natural disasters, and domestic violence, among other traumatic experiences that lead to altered behavioral states, such as chronic stress [3].

Mounting preclinical and clinical evidence supports a key role for the sustained activation of adrenergic-mediated signaling as a driver of tumor growth and progression, as well as decreased survival in various malignancies, including breast cancer [4-8]. Moreover, according to the literature, the global prevalence of depression hovers around $30 \%$ among breast cancer patients [9]. Chronic sympathetic nervous system (SNS) activation induces inflammatory processes in the tumor microenvironment (TM) of several cancers [10]. These (SNS and TM) are associated with the induction of growth-promoting signals primarily mediated by b-adrenergic receptors in tumor cells [11]. Thus, the SNS is a critical pathway by which chronic psychological stress can promote tumor growth [4].

Studies have identified possible environmental and lifestyle factors contributing to breast cancer diagnosis or disease progression, such as dietary choices, physical inactivity, and alcohol consumption [12-14]. There is growing evidence suggesting that depression and anxiety symptomatology in cancer patients are related to tumor and treatment-related inflammatory processes [12-14] that are known to induce tumor growth $[15,16]$. This is a crucial area to study due to the potential relationship between psychological distress and cancer progression.

Emerging evidence suggests that Hispanics are at higher risk of being exposed to traumatic SEA-related events than Non-Hispanic Whites (NHWs) in the form of child maltreatment and witnessing domestic violence [17]. Several studies have demonstrated a link between depression, anxiety [18], SEA, and markers of systemic inflammation [3] consistent with the Social Signal Transduction Theory of Depression [3]. This theory postulates that exposure to SEA modulates the systemic inflammatory activity and, in turn, induces symptoms of anxiety and depression. The social stressors most relevant to anxiety and depression, which are also linked to inflammation, are adverse childhood events (ACE), interpersonal loss, and social isolation [3]. Studies have shed light on the possibility that this link could lead to worse cancer health outcomes [19-23]. For example, chronic stress in breast cancer patients was related to accelerated disease progression $[6,24,25]$.

Various studies linked chronic stress, exposure to stressful events, and inflammation markers among breast cancer (BC) patients [26-30]. For example, a longitudinal pilot study found that participants with $B C(n=20)$ exposed to childhood trauma had significant depressive symptomatology and fatigue levels. These participants exhibited increased NF-kB pathway activation in peripheral blood mononuclear cells and had higher baseline levels of C-reactive protein, IL-6, and IL-1 in plasma [26]. Another study determined that BC patients $(n=16)$ with high stress (as measured by the Impact of Event Scale) after surgery exhibited increased myeloid-derived suppressor cells (MDSC) in the blood [27].

These cells help assemble the tumor microenvironment through various mechanisms (e.g., chemokine-regulated recruitment, the overproduction of cytokines, and the induction of $\mathrm{T}_{\text {reg }}$ cells) and contribute to tumor antigen-specific $\mathrm{T}$ cell non-responsiveness [28]. A longitudinal study revealed that a lack of social support (a form of social isolation) predicted higher IL-6 levels and depressive symptoms among BC survivors [29]. Furthermore, early relational stress exposure (represented by non-optimal parental bonding, such as rejection and neglect) was significantly associated with a positive lymph node status in a group of BC patients scheduled for surgery [30].

In sum, there is growing evidence supporting systemic inflammation as a common factor in depression, chronic psychosocial stress, and the sustained activation of the sympathetic nervous system. Recent work has highlighted the role of stress hormones in tumor progression [31]. However, very little is known about the interplay between SEA, 
depression, and anxiety on immune cells infiltration into the breast tumor microenvironment $[32,33]$. To address this gap, our study aimed to investigate the relationship between comorbid depression, anxiety, SEA, and immune cell infiltration (macrophages, B cells, and $\mathrm{T}$ cells) in the tumor microenvironment of Hispanic breast cancer patients.

\section{Methods}

Eligible participants were: (1) 21 years of age and older (the adult legal age in Puerto Rico), (2) females diagnosed with breast cancer, (3) donated tumor tissue for research, (4) not diagnosed with metastatic disease, and (5) had no documented or observed cognitive, visual, or physical impairment that would interfere with study participation. A total of 33 participants (power $>0.80, \mathrm{r}>0.35, \mathrm{a}=0.5$, two-sided) were recruited through the Ponce Research Institute-Puerto Rico Biobank (PRBB). The PRBB is a biorepository focused on biobanking biological specimens (fresh frozen tissues, paraffin blocks, high-quality tumor-derived RNA, and genomic DNA) of Hispanic cancer patients from Puerto Rico. The PRBB collects clinical and epidemiological data using medical chart reviews and selfreported surveys from patients recruited through a network of collaborators, including hospitals and oncology clinics. Eligible participants received an appointment to complete the informed consent (which included the PRBB permission to provide a specimen) and the data collection process.

After signing the informed consent, participants completed a series of self-reported questionnaires that included: (1) sociodemographic, lifestyle, and clinical information, (2) the Patient Health Questionnaire-9 (PHQ-9) [34], (3) the General Anxiety and Depression7 Scale (GAD-7) [35], (4) the Trauma History Questionnaire-Spanish Version (THQ) that measures exposure to three domains of traumatic events, such as sexual/physical abuse, exposure to crime, general disaster, and trauma [36], and; (5) the Adverse Childhood Experience Questionnaire (ACEQ) that measures exposure to the ten most common childhood adverse events [37].

The behavioral data collection process took approximately $60 \mathrm{~min}$; participants were provided a 5 -min break every $30 \mathrm{~min}$ or upon request. After completion, participants were provided with a stipend to compensate for their time and effort. The PRBB provided breast tumor samples (formalin-fixed paraffin-embedded) and clinical data extracted from the patients' medical charts, such as breast tumor stage, tumor size, and lymph node status.

Formalin-fixed paraffin-embedded tumor sections were stained for macrophage infiltration using CD68 (1:200; Dako, M0814), B cell infiltration with CD19 (1:100; Abcam, ab134114), and pan T cell infiltration with CD3 (1:100; Abcam, ab5690). Briefly, sections were fixed in $4{ }^{\circ} \mathrm{C}$ acetone for $10 \mathrm{~min}$ and rinsed with $1 \times$ PBS. Endogenous peroxide activity was blocked using $0.3 \% \mathrm{H} 202$ for $10 \mathrm{~min}$, followed by antigen retrieval with Citrate-EDTA buffer $\mathrm{pH} 6.2$ (CD68, CD3) or Tris-EDTA buffer pH 9.0 (CD19) for $40 \mathrm{~min}$ in a preheated water bath $\left(95-99^{\circ} \mathrm{C}\right)$. The slides were incubated with protein block solution for $1 \mathrm{~h}$ at room temperature.

Tissues were incubated with the respective primary antibodies overnight at $4{ }^{\circ} \mathrm{C}$ in a humidity chamber. Protein block, secondary antibody, and 3,3' Diaminobenzidine (DAB) in the Super Sensitive Link Label IHC kit (LP000-ULE, BioGenex, Fremont, CA) were used according to the manufacturer's instructions. All primary and secondary antibodies were diluted in PBS. Counterstain was performed using hematoxylin (Sigma, GHS316, St. Louis, $\mathrm{MO}, \mathrm{USA}$ ) for $5 \mathrm{~s}$, followed by washes with running tap water for $5 \mathrm{~min}$. The slides were dried, mounted, and blindly scored by investigators. For each patient sample, five random $20 \times$ high power fields were manually quantified for each marker with ImageJ software and averaged per slide.

Univariate descriptive analyses were used to explore the comorbid rates of depression (PHQ-9) scores $\geq 5$ and self-reported depression diagnosis in the past) and exposure to SEA (defined as having at least one ACE or one "yes' item reported in the THQ). The same analyses were employed to estimate the comorbid rates of anxiety (GAD-7 scores $\geq 5$ ) and exposure to SEA (ACE $\geq$ one $+\mathrm{THQ} \geq$ one). 
We analyzed these data using Spearman's rank correlation coefficient to determine an association between immune cell infiltration and comorbid depression, anxiety, or SEA. We compared continuous variables with the Mann-Whitney test. Categorical variables were assessed using the chi-square test. For this study, sample calculation was performed using the $G^{*}$ Power tool. For each statistical assessment power $>0.80$ to detect $r>0.35$ with $n=32$, $\mathrm{a}=0.5$, and a two-sided test. A $p$-value of 0.05 was considered statistically significant.

\section{Results}

Table 1 summarizes the participants' sociodemographic and clinical characteristics and correlations among behavioral outcome variables (depression, anxiety, and exposure to SEA). The participants' mean age was $62.8(\mathrm{SD}=10.58)$. The majority of women reported being married $(60.6 \%)$ and retired from employment $(45.5 \%)$, followed by unemployed $(18.2 \%)$ and currently employed $(18.2 \%)$. Most participants reported an annual income ranging from $\$ 19,001-\$ 35,000(45.5 \%)$, followed by an income of equal or less than $\$ 19,000(42.4 \%)$.

Table 1. Participants' characteristics and correlations with behavioral outcome variables.

\begin{tabular}{|c|c|c|c|c|c|c|c|c|}
\hline Variables & Mean/SD, N/\% & $\begin{array}{l}\text { PHQ-8 } \\
(\mathrm{N}=33)\end{array}$ & $\begin{array}{l}\text { GAD-7 } \\
(\mathbf{N}=33)\end{array}$ & $\begin{array}{l}\text { HX. De- } \\
\text { pression } \\
(\mathrm{N}=33)\end{array}$ & $\begin{array}{c}\text { ACE } \\
(N=33)\end{array}$ & $\begin{array}{c}\text { THQ } \\
(\mathrm{N}=33)\end{array}$ & $\begin{array}{c}\text { ACE + De- } \\
\text { pression } \\
(N=33)\end{array}$ & $\begin{array}{c}\text { THQ + } \\
\text { Depres- } \\
\text { sion } \\
(\mathrm{N}=33)\end{array}$ \\
\hline \multicolumn{9}{|l|}{ Socio-Demographic } \\
\hline Age & $62.8(\mathrm{SD}=10.58)$ & -0.223 & -0.194 & & 0.073 & 0.099 & & \\
\hline Civil Status: Married & $18(57.6 \%)$ & 1.312 & 0.788 & 0.001 & 0.418 & & 0.034 & 0.137 \\
\hline With Employment & $8(24.2 \%)$ & 0.792 & 1.676 & 0.090 & 1.161 & & 1.676 & 0.015 \\
\hline Income $(\leq 19,000)$ & $14(42.4 \%)$ & 0.248 & 0.698 & 1.146 & 2.068 & & $4.467 *$ & 1.146 \\
\hline Income Enough (Yes) & $14(42.4 \%)$ & 0.104 & 0.001 & 0.001 & 0.020 & & 0.034 & 0.137 \\
\hline \multicolumn{9}{|l|}{ Clinical Characteristics } \\
\hline Tumor Size $(\mathrm{cm})$ & $3.19(\mathrm{SD}=2.8)$ & -0.242 & -0.350 & & -0.096 & -0.231 & & \\
\hline Lymph Nodes & $7(21.2 \%)$ & 0.046 & 0.377 & 0.326 & 0.326 & & 0.029 & 0.326 \\
\hline Chemo-Therapy & $9(27.3 \%)$ & 0.280 & 0.009 & 1.296 & $3.764^{*}$ & & 0.836 & 0.836 \\
\hline Radiotherapy & $3(9.1 \%)$ & 0.172549 & 0.014 & 0.647 & 0.416 & & 0.027 & 0.416 \\
\hline $\begin{array}{c}\text { Cancer Hormonal } \\
\text { Therapy }\end{array}$ & $6(18.2 \%)$ & 2.363 & 0.141 & 0.933 & 0.117 & & 0.117 & 0.933 \\
\hline Menopause Status (Yes) & $21(63.6 \%)$ & 2.444 & 0.932 & $5.917 *$ & 2.437 & & $6.559 *$ & $5.917 *$ \\
\hline BMI & $30.59(\mathrm{SD}=4.8)$ & 0.128 & 0.105 & & -0.102 & 0.055 & & \\
\hline $\begin{array}{l}\text { Mental Health Diagnosis } \\
\text { (Yes) }\end{array}$ & $9(27.3 \%)$ & 0.027 & 1.088 & $7.637^{* *}$ & $4.641 *$ & & $13.206^{* *}$ & $7.637^{* *}$ \\
\hline $\begin{array}{c}\text { Current Mental Health } \\
\text { Services }\end{array}$ & $5(15.2 \%)$ & 1.886 & 1.245 & 0.001 & 0.157 & & 0.262 & 0.001 \\
\hline $\begin{array}{c}\text { Mental Health Services } \\
\text { (Past) }\end{array}$ & $13(39.4 \%)$ & 0.016 & 1.172 & $4.406^{*}$ & 1.528 & & $5.629 * *$ & $4.406 *$ \\
\hline \multicolumn{9}{|l|}{$\begin{array}{c}\text { Current Self-Reported } \\
\text { Medication Use }\end{array}$} \\
\hline Ssri's & $7(21.2 \%)$ & 0.090 & 0.287 & 0.287 & 0.007 & & 0.012 & 0.044 \\
\hline Aspirin & $11(33.3 \%)$ & 1.320 & 1.450 & 0.090 & 0.687 & & 0.071 & 0.253 \\
\hline Statins & $9(27.3 \%)$ & 0.557 & 0.556 & 0.007 & 0.229 & & 0.053 & 0.132 \\
\hline $\begin{array}{l}\text { High Blood Pressure } \\
\text { Medication }\end{array}$ & $16(48.5 \%)$ & 0.831 & 0.267 & 1.410 & 1.637 & & 1.962 & 0.046 \\
\hline Contraceptives & $1(3 \%)$ & 3.223 & 0.277 & 0.277 & 2.750 & & 0.448 & 1.586 \\
\hline Hormone Replacement & $5(15.2 \%)$ & 0.797 & 1.244 & $5.305^{*}$ & 0.157 & & 2.460 & 1.244 \\
\hline $\begin{array}{c}\text { Sleep Hours Per Day }(\geq 8 \\
\text { or }<6)\end{array}$ & $\begin{array}{l}7(21.2 \%) 26 \\
\quad(78.8 \%)\end{array}$ & 1.676 & 2.392 & 1.172 & 0.755 & & 3.030 & 1.172 \\
\hline $\begin{array}{l}\text { Smoking Behavior in the } \\
\text { Past } 6 \text { Months (Yes) }\end{array}$ & $4(12.1 \%)$ & 0.001 & $7.880 * *$ & 2.25 & 1.70 & & 0.836 & 0.214 \\
\hline $\begin{array}{l}\text { Alcohol Consumption in } \\
\text { the Past } 6 \text { Months (Yes) }\end{array}$ & $10(30.3 \%)$ & $5.18 *$ & 0.663 & 3.03 & 0.054 & & 2.63 & $5.62 *$ \\
\hline
\end{tabular}

Moreover, $56.6 \%$ of the participants reported that their annual income was not enough to cover their basic family needs. Although Puerto Rico is considered a wealthy region of Latin America, as a USA territory, it has a significantly higher poverty rate (43.5\%) 
compared to other USA territories (US Virgin Islands $=22.4 \%$ and Guam $=22.9 \%$ ) [38]. Regarding clinical characteristics: $21.2 \%$ of participants were diagnosed with a T2 cancer stage, followed by T1c (15.2\%). Lastly, $21.2 \%$ of the sample reported positive lymph node status.

Regarding depressive symptomatology as assessed by PHQ-9, 20\% reported depressive symptoms (from mild to severe), and $21 \%$ reported experiencing anxiety symptoms (GAD-7). The THQ results showed that $100 \%$ of participants reported at least one SEA event, and $72.7 \%$ reported exposure to two or more SEA events. Additionally, $47 \%$ reported exposure to crime events, $94 \%$ reported exposure to general disaster/trauma events, and $73 \%$ reported exposure to physical/sexual abuse events (33\% was sexual abuse and 67\% was physical abuse). A further $30 \%$ reported a comorbid history of depression symptoms and ACE scores, 39\% reported comorbid trauma history (THQ) and depression symptoms, while $21 \%$ reported a history of trauma and anxiety symptoms. Meanwhile, $72 \%$ reported exposure to one or more ACE (ACEQ), with 27\% reporting four or more events for a mean score of $2.36(\mathrm{SD}=2.56)$.

Data (Table 1) also showed that depression symptoms plus ACE scores $(p<0.001)$ and a comorbid history of depression plus THQ scores $(p<0.01)$ significantly correlated with reporting a mental health diagnosis. Sixty-one percent of participants who reported having received mental health services in the past also reported comorbid THQ and depression. In addition, past mental health services were significantly correlated to comorbid depression symptoms plus ACE scores $(p=0.01)$, to comorbid depression symptoms plus THQ scores $(p<0.01)$, and to a history of depression alone $(p<0.01)$.

On the other hand, we found a positive, statistically significant relationship between alcohol consumption in the past six months and comorbid trauma history and history of depression diagnosis $(p=0.01)$. A total of $70 \%$ of participants reporting alcohol consumption also reported comorbid trauma history and depression diagnosis.

We also assessed if a relationship existed between intra-tumoral infiltrates representative of the innate (macrophage) and adaptive (B cell and $\mathrm{T}$ cell) immune response and clinicopathological variables (Figure 1 and Table 2). Figure 1 shows representative images of macrophages (CD68), B cells (CD19), and T cells (CD3) in our cohort. Our data show that an increased tumoral infiltration of $\mathrm{T}$ cells and decreased $\mathrm{B}$ cell infiltration were positively associated with increased age $(p<0.01)$. Macrophage infiltration was associated with postmenopausal status $(p<0.05)$, active chemotherapy $(p<0.01)$, and positive lymph nodes $(p<0.05)$. Macrophage infiltration was associated with past mental health services $(p<0.05)$ and lack of social support $(p<0.05)$.

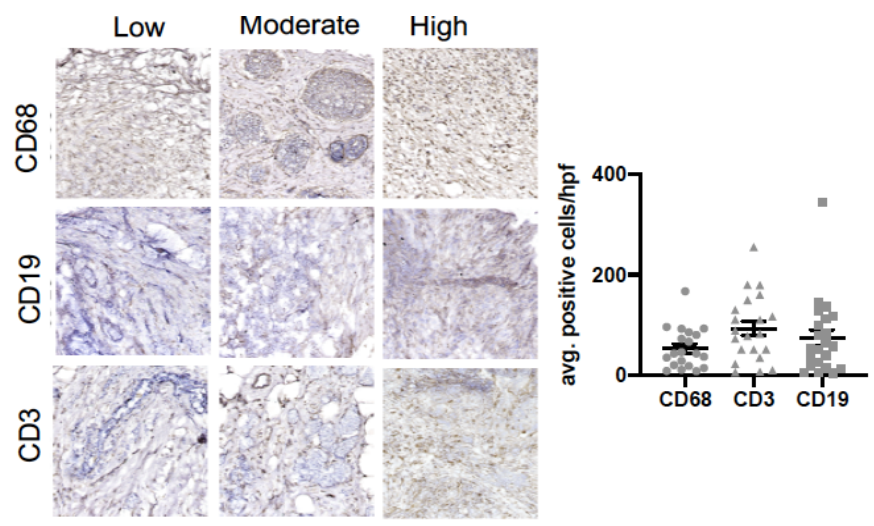

Figure 1. B cell, T cell and macrophage infiltration in breast tumor samples. Immunohistochemical analysis of breast tumor samples showing expression of CD68+ (macrophages), CD19+ (B cells) and CD3+ (T cells) cells. 
Table 2. Correlations among immune infiltration markers and known behavioral and biological mediators/moderators.

\begin{tabular}{|c|c|c|c|}
\hline Variables & $\begin{array}{l}\text { CD68 } \\
\text { Macrophages }\end{array}$ & CD3 T-Cells & CD19 B-Cells \\
\hline \multicolumn{4}{|l|}{ Known biological mediators/moderators } \\
\hline Age & 0.090 & $0.528 * *$ & $-0.460 *$ \\
\hline BMI & 0.184 & 0.2816 & -0.012 \\
\hline Menopause status & $9.000 *$ & 21.500 & 21.000 \\
\hline Tumor size & 0.511 & -0.118 & 0.011 \\
\hline Cancer treatment: Chemotherapy & $0.000 * *$ & 9.000 & 4.000 \\
\hline Cancer treatment: Radiation Therapy & 13.000 & 12.000 & 12.000 \\
\hline Cancer treatment: Hormonal Therapy & 10.000 & 10.000 & 9.000 \\
\hline Lymph node status & $3.000 *$ & 19.000 & 7.000 \\
\hline SSRI's & 41.000 & 167.000 & 40.000 \\
\hline Aspirin & 15.000 & 51.5000 & 41.000 \\
\hline Statins & 40.000 & 64.000 & 45.000 \\
\hline High blood pressure medication & 33.000 & 44.000 & 39.000 \\
\hline Contraceptives & 2.000 & 4.000 & 2.000 \\
\hline Hormone replacement & 26.000 & 23.000 & 24.000 \\
\hline Sleep hours per day & 33.000 & 28.500 & 35.000 \\
\hline \multicolumn{4}{|l|}{ Known behavioral mediators/moderators } \\
\hline Current use of stress management skills & 37.000 & 42.5000 & 39.000 \\
\hline Mental health services (present) & 16.000 & 9.500 & 1.000 * \\
\hline Mental health services (past) & $15.000 *$ & 35.500 & 39.000 \\
\hline Smoking behavior & 22.000 & 21.000 & 25.000 \\
\hline Alcohol consumption & 29.000 & 39.000 & 37.000 \\
\hline
\end{tabular}

Aiming to explore the impact of SEA on the infiltration of immune cells into the tumor microenvironment, we explored potential correlations between SEA exposures, depression, and anxiety with macrophages, $\mathrm{T}$ cells, and $\mathrm{B}$ cells (see Table 3). In this context, we found that increased macrophage infiltration was significantly associated with depression symptoms $(p<0.05)$, while increased B cell infiltration was significantly associated with exposure to ACE $(p<0.05)$.

Table 3 illustrates the correlations between depression, anxiety, and categories of exposure to SEA. Our data show that increased B cell infiltration was significantly associated with comorbid exposure to crime and anxiety symptoms $(p<0.05)$. There was a statistically significant relationship between increased $\mathrm{T}$ cell infiltration and comorbid exposure to physical/sexual abuse and anxiety symptoms $(p<0.05)$.

Table 3. Correlations among depression, anxiety, exposure to SEA, and immune cell infiltrates.

\begin{tabular}{llll}
\hline Variables & $\begin{array}{l}\text { CD68 } \\
\text { Macrophages }\end{array}$ & CD3 T-Cells & CD19 B-Cells \\
\hline $\begin{array}{lll}\text { PHQ-8 total score (depression symptoms) } \\
\text { Depression symptoms (current) }\end{array}$ & 0.224 & $0.466^{*}$ & 0.581 \\
$\begin{array}{l}\text { Hx. of Depression } \\
\text { GAD-7 total score (anxiety symptoms) }\end{array}$ & 32.000 & 33.500 & 33.000 \\
$\begin{array}{l}\text { Adverse Childhood Events (ACE, total } \\
\text { score) }\end{array}$ & 0.098 & 49.000 & 44.000 \\
$\begin{array}{l}\text { Trauma History Questionnaire (THQ, total } \\
\text { score) }\end{array}$ & -0.805 & 0.013 & 0.189 \\
$\begin{array}{l}\text { THQ/Crime-related events (total score) } \\
\text { THQ/Crime-related events (average age) }\end{array}$ & 0.163 & 0.886 & 0.457 \\
$\begin{array}{l}\text { THQ/General disasters and trauma (total } \\
\text { score) }\end{array}$ & - & 0.015 & 0.173 \\
$\begin{array}{l}\text { THQ/General disasters and trauma } \\
\text { (average age) }\end{array}$ & & 0.067 & 0.216 \\
\hline
\end{tabular}


Table 3. Cont.

\begin{tabular}{|c|c|c|c|}
\hline Variables & $\begin{array}{l}\text { CD68 } \\
\text { Macrophages }\end{array}$ & CD3 T-Cells & CD19 B-Cells \\
\hline $\begin{array}{l}\text { THQ/Physical and Sexual experiences (total } \\
\text { score) }\end{array}$ & 0.067 & 0.288 & -0.034 \\
\hline \multicolumn{4}{|l|}{$\begin{array}{l}\text { THQ/Physical and Sexual experiences } \\
\text { (average age) }\end{array}$} \\
\hline Comorbid ACE + Hx. of Depression & 30.000 & 32.500 & 26.000 \\
\hline Comorbid ACE + Anxiety & 20.000 & 23.500 & 16.000 \\
\hline Comorbid THQ/Crime + Hx. of Depression & 24.000 & 28.000 & 34.000 \\
\hline Comorbid THQ/Crime + Anxiety & 18.000 & 22.000 & 10.000 * \\
\hline $\begin{array}{l}\text { Comorbid THQ/Disaster and trauma }+\mathrm{Hx} \text {. } \\
\text { of Depression }\end{array}$ & 32.000 & 49.500 & 34.000 \\
\hline $\begin{array}{l}\text { Comorbid THQ/Disaster and trauma + } \\
\text { Anxiety }\end{array}$ & 20.000 & 23.500 & 16.000 \\
\hline $\begin{array}{l}\text { Comorbid THQ/Physical and sexual abuse } \\
+ \text { Hx. of Depression }\end{array}$ & 32.000 & 49.500 & 34.000 \\
\hline $\begin{array}{l}\text { Comorbid THQ/Physical and sexual abuse } \\
+ \text { Anxiety }\end{array}$ & 12.000 & $8.000 *$ & 20.000 \\
\hline
\end{tabular}

Figure 2 illustrates the distribution of comparisons between macrophages (CD68+ cells), T cells (CD3+ cells), and B cells (CD19+ cells) with ACE plus depression, ACE plus anxiety, and history of trauma (THQ) plus ACE. Analyses did not yield significant results; however, the ACE plus anxiety group presented the most infiltration of the three types of immune cells $(p=0.06)$.

a

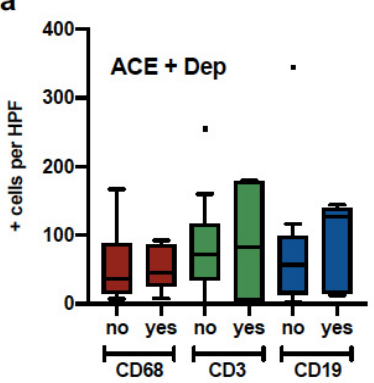

b

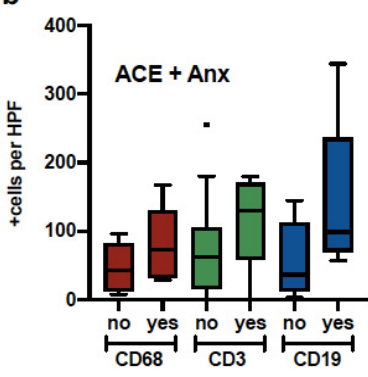

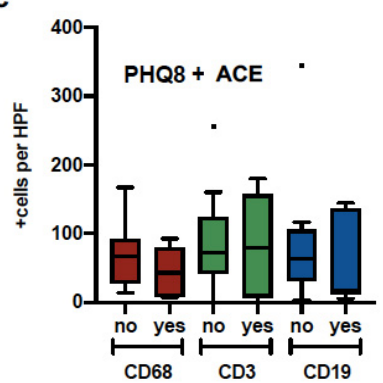

Figure 2. Macrophage, $T$ cell and B cell expression in patients with psychological distress. Tumor samples from breast cancer patients were quantified for Macrophage (CD68), B cells (CD19) and T cells (CD3) and divided into groups a) Elevated ACE and history of depression, b) Elevated ACE and GAD7, c) Elevated PHQ8 and Elevated ACE.

\section{Discussion}

The goal of this study was to examine whether breast cancer patients exposed to social environmental adversity (SEA, e.g., child abuse, crime, and sexual and physical violence) and reporting symptoms of depression and anxiety correlated with immune cells infiltration in the breast tumor microenvironment. Our work builds from existing data suggesting that the physiological stress response via chronic activation of the SNS and the hypothalamic-pituitary-adrenal (HPA) axis promotes inflammatory responses that lead to tumor growth and progression $[6,23,24,39]$.

In our study, the rates of anxiety and depression symptoms among study participants were similar to those reported previously by breast cancer patients in a systematic review [40]. The rates of ACE were comparable to Hispanic women in the US [41,42]. However, our sample reported higher rates of ACE events (at least one event) when compared to ACE events reported by other groups of breast cancer patients $[43,44]$. Our sample reported an outstanding rate of four or more ACE. This outcome can be related to the increased risk 
of developing chronic conditions compared to Puerto Ricans without cancer included in other studies, such as the Study of Latino (SOL) cohort (27\%, vs. $38.1 \%$, respectively) [41].

Moreover, this risk is higher than for overall Hispanic men (25.8\%) and other Hispanic sub-ethnicities (e.g., Cubans: 20.2\% and South Americans: 24.0\%) included in the SOL [45] the other hand, rates of exposure to SEA $(100 \%$, at least one SEA) were high. Interestingly, $73 \%$ reported lifetime exposure to physical/sexual abuse, and, out of these, 33\% reported being exposed to sexual assault, and $67 \%$ reported being exposed to physical assaults. While the rates of lifetime sexual assault (33\%) in our study were similar to the US national rates among Hispanic women (35.6\%) [45]; the rate of physical assault in our sample was significantly higher than the rate of physical abuse reported by Hispanic women who participated in the Sexual Assault Among Latinas Study (SALAS study, 67\% vs. 25.6\%, respectively) [46].

Likewise, the rates of overall physical/sexual assaults were higher in our sample of Hispanic breast cancer patients when compared to Hispanic women in the SALAS study (73\% vs. $66.2 \%$, respectively) [47]. Overall, these findings suggest that, as a whole, our study sample was similar to the general and Hispanic population in terms of the rates of anxiety and depression symptoms, ACE, and sexual assault. However, higher rates of exposure to physical/sexual assault exposure among our sample of Hispanic breast cancer patients warrants further research to elucidate if these rates are comparable to the general population of women living in Puerto Rico.

We found a positive relationship between depression symptoms and the infiltration of macrophages into the tumor microenvironment. Macrophages (M1) are significant contributors to neuroinflammatory processes linked to major depression symptoms [48]. On the other hand, ACE exposure was significantly correlated with increased B cell infiltration. Compared to patients not reporting $\mathrm{ACE}$ and anxiety comorbidity, the ACE + Anxiety group had elevated B cell, $\mathrm{T}$ cell, and macrophage infiltration, although this was marginally significant $(p=0.06)$. Moreover, anxiety symptoms combined with exposure to crime or exposure to physical and sexual abuse were significantly associated with $\mathrm{B}$ cell and $\mathrm{T}$ cell infiltration, respectively.

These findings pose a potential clinical and translational value as evidence supports the role of immune infiltrates in promoting breast tumor progression [46,47]. For example, CD4+ FOXP3+, CD4+, Th2 cells, macrophages, and MDSC cells promote growth by activating synergistic pathways between the immune microenvironment and tumor cells [49]. An analysis of almost 11,000 tumor samples showed that $\mathrm{T}$ regulatory cells and $\mathrm{M} 0$ and M2 macrophages were associated with a lack of response to chemotherapy, even after controlling for the estrogen receptor (ER) status [50]. Existing theories of tumor-infiltrating immune cells promoting tumor proliferation have identified other mechanisms of breast cancer invasion and metastasis [51].

For example, macrophages can induce cell migration and invasion through the epidermal growth factor (EGF) and promote angiogenesis by releasing VEGF. Another study suggested that immune cell-mediation through IL-4-expressing CD4+ T lymphocytes indirectly promotes breast cancer tumor invasion and further metastasis [48]. Furthermore, there is evidence that aberrant lymphocyte infiltration induced focal capsule disruptions to contribute to breast cancer tumor progression and invasion [48]. Recent studies have shown that B cells and regulatory B cells selectively promote breast cancer lymph node metastasis [52], implicating them in the metastatic process [53].

The primary limitation of this study is the small sample size that limits our ability to include potential confounders in multivariate analyses. Despite this limitation, sufficient power was apparent to detect significant correlations between the independent variable (exposure to SEA: ACE + THQ) and the primary outcomes (depression, anxiety, and immune cell infiltrates in the breast tumor microenvironment). Despite being a small sampled-sized study, we found that the rates of potential socio-behavioral risk factors (depression, anxiety, and SEA exposure) were similar to US general and Hispanic cancer patients and women populations. 
Future studies with larger patient numbers and a longitudinal design are needed to determine whether the combination of exposure to SEA, symptoms of anxiety, and depression can modulate the breast tumoral infiltration of cells from the innate and adaptive immune response. Another limitation of our study is the lack of additional strategies (RNAor Exome-seq) or specific markers for determining immune cell sub-types (such as M1 or M2 macrophages, CD4+ or CD8+ T cells, among others). For example, we plan on performing RNA-seq on tumor samples to classify immune cell subtypes in tumor samples, as these analyses will complement and expand our current IHC-based approach. Moreover, follow-ups of larger-sampled work from our group will aim to determine if there are associations between ACE, anxiety, and depression with specific immune cell types, such as CD4+ or CD8+ T cells, M1/M2 macrophages, and specific B cells subtypes.

Despite these limitations, this study's findings significantly contribute to the body of evidence regarding the link between depression, anxiety, SEA exposure, and breast cancer progression. Others have shown that chronic sympathetic nervous system activation leads to increased immune inflammation levels in tumors, including the breast cancer tumor microenvironment [9]. This process has been associated with the induction of growthpromoting signals primarily mediated by b-adrenergic receptors in tumor cells [11]. This is why a longitudinal study with a larger sample size is needed to elucidate the potential moderating role of exposure to SEA in the relationship between anxiety and depression symptoms and immune markers of breast cancer progression.

This study's aims were partially guided by the Social Signal Transduction Theory of Depression [3], which was modified and applied to breast cancer patients. According to this theory, the innate immune response to physical predatory threats can be activated by modern-day social, symbolic, anticipated, and imagined threats and responses to contemporary chronic social-environmental adversity (e.g., ACE and physical and sexual abuse) that results in systemic inflammation [3]. A key component of this theory is the neuroinflammatory-sensitization to the adversity paradigm [3]. Neural responses to contemporary chronic SEA may up-regulate systemic inflammation [3].

Chronic SEA is represented in specific brain regions that initiate and modulate inflammatory activity and, in turn, induce cognitive, emotional, and behavioral symptoms of anxiety and depression [3]. As such, neural systems involved in processing social threats (e.g., the anterior insula and dorsal anterior cingulate cortex) have an anatomical connection to lower levels of the brain region, such as the hypothalamus and brainstem, which, in turn, influence systemic inflammation through activities of the HPA axis and the SNS [3]. Exposure to ACE has been associated with chronic activation of the HPA axis during sensitive developmental periods leading to epigenetic changes in the glucocorticoid receptor [52].

A life-course prospective cohort study $(n=1037)$ [54] found that the cumulative exposure to early life trauma was associated with elevated levels of C-reactive Protein $(\mathrm{RR}=1.59 ; 95 \% \mathrm{CI}=1.02-2.50)$. Those who were exposed to ACE were more likely to experience more stress during adulthood [54]. A cancer diagnosis is a life-threatening event that can cause a tremendous emotional burden on the patient [55]. The theory's neuroinflammatory-sensitization to adversity paradigm applied to the cancer experience may provide insights into known and novel biopsychosocial pathways (e.g., SEA, anxiety, depression, and adrenergic-mediated signaling) by which current and past exposure to chronic stress among breast cancer patients may lead to inflammatory phenotypes and cancer progression.

\section{Conclusions}

These findings support a role for SEA, symptoms of anxiety, and depression as potential modulators of the immune tumor microenvironment in breast cancer. These results provide the rationale for further studies in this area and represent a potential venue for intervention at the clinic. For example, our data supports developing further lager-sampled clinical studies to determine if exposure to SEA represent a risk factor for breast cancer 
progression. Our findings also support the clinical value of screening for (1) SEA, anxiety, and depression; and (2) inflammatory immune infiltrates in tumors, as these have been associated with worse outcomes in several cancers.

Future studies may consider pharmacological and psychological approaches to prevent the effects of SNS or HPA activation on the immune tumor microenvironment among breast cancer patients exposed to SEA and presenting anxiety and depression symptoms. Future studies should also consider the implication of these findings among other racial/ethnic groups, especially among African American women with breast cancer, as evidence shows that this racial/ethnic minority presents high rates of exposure to SEA [14].

Author Contributions: E.M.C.-F. and G.N.A.-P. conceived and designed the research. K.I.A. performed the data collection process. I.F. and Z.R. contributed to participants' recruitment and breast tissue accrual. E.M.C.-F., G.N.A.-P., K.I.A., C.I.P.-V., N.T.-B., I.F., M.I.L. and H.J. wrote and revised the manuscript. C.I.P.-V. and K.I.A. contributed to the statistical analysis. C.B.C.-E., L.M. and A.N.A.-A. performed immunohistochemical analyses. All authors provided intellectual input. All authors have read and agreed to the published version of the manuscript.

Funding: This research was funded by the National Institute of Minority Health and Health Disparities, grant number 5G12MD007579-33 and 2U54MD007579-34, and R21MD013674. G.N.A.-P. was additionally supported by the following grants from the National Cancer Institute: U54CA163071, U54CA163068, and R21CA253555. C.B.C.-E. and A.N.A.-A. were supported by the National Institute of General Medicine Sciences (R25GM082406), and the Intellectus Foundation. C.B.C.-E. was additionally supported by the National Cancer Institute (F31CA232622).

Institutional Review Board Statement: The study was conducted according to the guidelines of the Declaration of Helsinki and approved by the Institutional Review Board of Ponce Health Sciences University-Ponce Research Institute (protocol code 170411-EC) approved on 18 July 2017.

Informed Consent Statement: Informed consent was obtained from all subjects involved in the study.

Data Availability Statement: The data presented in this study will be available in this article.

Acknowledgments: The team acknowledges the Ponce Research Institute's editorial team for providing editorial assistance.

Conflicts of Interest: The authors declare no conflict of interest. The funders had no role in the design of the study; in the collection, analyses, or interpretation of data; in the writing of the manuscript, or in the decision to publish the results.

\section{References}

1. Bray, F.; Ferlay, J.; Soerjomataram, I.; Siegel, R.L.; Torre, L.A.; Jemal, A. Global cancer statistics 2018: GLOBOCAN estimates of incidence and mortality worldwide for 36 cancers in 185 countries. CA Cancer J. Clin. 2018, 68, 394-424. [CrossRef] [PubMed]

2. Miller, K.D.; Goding Sauer, A.; Ortiz, A.P.; Fedewa, S.A.; Pinheiro, P.S.; Tortolero-Luna, G.; Martinez-Tyson, D.; Jemal, A.; Siegel, R.L. Cancer statistics for hispanics/latinos, 2018. CA Cancer J. Clin. 2018, 68, 425-445. [CrossRef] [PubMed]

3. Slavich, G.M.; Irwin, M.R. From Stress to Inflammation and Major Depressive Disorder A Social Signal Transduction Theory of Depression. Psychol. Bull. 2014, 140, 774-815. [CrossRef] [PubMed]

4. Cole, S.W.; Nagaraja, A.S.; Lutgendorf, S.K.; Green, P.A.; Sood, A.K. Sympathetic nervous system regulation of the tumour microenvironment. Nat. Rev. Cancer 2015, 15, 563-572. [CrossRef]

5. Antonova, L.; Aronson, K.; Mueller, C.R. Stress and breast cancer: From epidemiology to molecular biology. Breast Cancer Res. 2011, 13, 208. [CrossRef]

6. Obeid, E.I.; Conzen, S.D. The role of adrenergic signaling in breast cancer biology. Cancer Biomark. 2013, 13, 161-169. [CrossRef]

7. Armaiz-Pena, G.N.; Lutgendorf, S.K.; Cole, S.W.; Sood, A.K. Neuroendocrine modulation of cancer progression. Brain Behav. Immun. 2009, 23, 10-15. [CrossRef]

8. Antoni, M.H.; Lutgendorf, S.K.; Cole, S.W.; Dhabhar, F.S.; Sephton, S.E.; McDonald, P.G.; Sood, A.K.; Stefanek, M. The influence of bio-behavioural factors on tumour biology: Pathways and mechanisms. Nat. Rev. Cancer 2006, 6, 240-248. [CrossRef]

9. Powell, N.D.; Tarr, A.J.; Sheridan, J.F. Psychosocial stress and inflammation in cancer. Brain Behav. Immun. 2013, 30, S41-S47. [CrossRef]

10. Pilevarzadeh, M.; Amirshahi, M.; Afsargharehbagh, R.; Rafiemanesh, H.; Hashemi, S.M.; Balouchi, A. Global prevalence of depression among breast cancer patients: A systematic review and meta-analysis. Breast Cancer Res. Treat. 2019, 176, 519-533. [CrossRef] 
11. Cole, S.W.; Sood, A.K. Molecular Pathways: Beta-Adrenergic Signaling in Cancer. Clin. Cancer Res. 2012, 18, 1201-1206. Available online: http:/ / clincancerres.aacrjournals.org/content/18/5/1201.abstract (accessed on 1 October 2020). [CrossRef] [PubMed]

12. Bouchard, L.C.; Antoni, M.H.; Blomberg, B.B.; Stagl, J.M.; Gudenkauf, L.M.; Jutagir, D.R.; Carver, C.S.; Derhagopian, R.P.; Glück, S.; Lechner, S.; et al. Postsurgical Depressive Symptoms and Proinflammatory Cytokine Elevations in Women Undergoing Primary Treatment for Breast Cancer. Psychosom. Med. 2016, 78, 26-37. [CrossRef] [PubMed]

13. Torres, M.A.; Pace, T.W.; Liu, T.; Felger, J.C.; Mister, D.; Doho, G.H.; Kohn, J.N.; Barsevick, A.M.; Long, Q.; Miller, A.H. Predictors of depression in breast cancer patients treated with radiation: Role of prior chemotherapy and nuclear factor kappa B. Cancer 2013, 119, 1951-1959. [CrossRef] [PubMed]

14. Fagundes, C.; LeRoy, A.; Karuga, M.; Armer, J.M. Behavioral Symptoms after Breast Cancer Treatment: A Biobehavioral Approach. J. Pers. Med. 2015, 5, 280-295. [CrossRef]

15. Qiao, Y.; He, H.; Jonsson, P.; Sinha, I.; Zhao, C.; Dahlman-Wright, K. AP-1 is a key regulator of proinflammatory cytokine TNF $\alpha$-mediated triple-negative breast cancer progression. J. Biol. Chem. 2016, 291, 5068-5079. [CrossRef]

16. Hsieh, N.-T.; Huang, C.-Y.; Li, C.-I.; Weng, Y.-T.; Lee, M.-F. MED28 Regulates Proinflammatory Cytokine-induced EpithelialMesenchymal Transition and Invasion in Human Breast Cancer Cells. FASEB J. 2017, 31, 809.16. [CrossRef]

17. Roberts, A.L.; Gilman, S.E.; Breslau, J.; Breslau, N.; Koenen, K.C. Race/ethnic differences in exposure to traumatic events, development of post-traumatic stress disorder, and treatment-seeking for post-traumatic stress disorder in the United States. Psychol. Med. 2011, 41, 71-83. [CrossRef]

18. Michopoulos, V.; Powers, A.; Gillespie, C.F.; Ressler, K.J.; Jovanovic, T. Inflammation in Fear- and Anxiety-Based Disorders: PTSD, GAD, and Beyond. Neuropsychopharmacology 2017, 42, 254-270. [CrossRef]

19. Bortolato, B.; Hyphantis, T.; Valpoine, S.; Caravalho, A. Depression in cancer: The many biobehavioral pathways driving tumor progression. Cancer Treat. Rev. 2017, 52, 58-70. [CrossRef]

20. Sotelo, J.L.; Musselman, D.; Nemeroff, C. The biology of depression in cancer and the relationship between depression and cancer progression. Int. Rev. Psychiatry 2014, 26, 16-30. [CrossRef]

21. Aldea, M.; Craciun, L.; Tomuleasa, C.; Crivii, C. The role of depression and neuroimmune axis in the prognosis of cancer patients. J BUON 2014, 19, 5-14. [PubMed]

22. Rua Rodrigues, A.; Cristina Trufelli, D.; Fonseca, F.; de Carvalho, L.; Giglio, A. Fatigue in Patients With Advanced Terminal Cancer Correlates with Inflammation, Poor Quality of Life and Sleep, and Anxiety/Depression. Am. J. Hosp. Palliat. Med. 2015, 33, 942-947. [CrossRef] [PubMed]

23. Armer, J.S.; Schrepf, A.; Cuneo, M.G.; Christensen, D.; Thaker, P.H.; Slavich, G.M.; Lutgendorf, S.K. Anxiety levels parallel changes in inflammation over time in ovarian cancer patients. Brain Behav. Immun. 2017, 66, e27-e28. [CrossRef]

24. Lamkin, D.M.; Sung, H.Y.; Yang, G.S.; David, J.M.; Ma, J.C.; Cole, S.W.; Sloan, E.K. $\alpha 2$-Adrenergic blockade mimics the enhancing effect of chronic stress on breast cancer progression. Psychoneuroendocrinology 2017, 51, 262-270. [CrossRef] [PubMed]

25. Butler, L.D.; Koopman, C.; Classen, C.; Spiegel, D. Traumatic stress, life events, and emotional support in women with metastatic breast cancer: Cancer-related traumatic stress symptoms associated with past and current stressors. Heal. Psychol. 1999, 18, 555-560. [CrossRef]

26. Han, T.J.; Felger, J.C.; Lee, A.; Mister, D.; Miller, A.H.; Torres, M.A. Association of childhood trauma with fatigue, depression, stress, and inflammation in breast cancer patients undergoing radiotherapy. Psychooncology 2015, 25, 187-193. [CrossRef]

27. Mundy-Bosse, B.L.; Thornton, L.M.; Yang, H.-C.; Andersen, B.L.; Carson, W.E. Psychological stress is associated with altered levels of myeloid-derived suppressor cells in breast cancer patients. Cell Immunol. 2011, 270, 80-87. [CrossRef]

28. Kumar, V.; Patel, S.; Tcyganov, E.; Gabrilovich, D.I. The Nature of Myeloid-Derived Suppressor Cells in the Tumor Microenvironment. Trends Immunol. 2016, 37, 208-220. [CrossRef]

29. Hughes, S.; Jaremka, L.M.; Alfano, C.M.; Glaser, R.; Povoski, S.P.; Lipari, A.M.; Agnese, D.M.; Farrar, W.B.; Yee, L.D.; KiecoltGlaser, J.K. Social support predicts inflammation, pain, and depressive symptoms: Longitudinal relationships among breast cancer survivors. Psychoneuroendocrinology 2014, 42, 38-44. [CrossRef]

30. Renzi, C.; Vadilonga, V.; Gandini, S.; Perinel, G.; Rotmensz, N.; Didier, F.; Rescigno, M.; Pravettoni, G. Stress exposure in significant relationships is associated with lymph node status in breast cancer. PLoS ONE 2016, 11, e0149443. [CrossRef]

31. Valente, V.B.; Verza, F.A.; Lopes, F.Y.; Ferreira, J.Z.; Dos Santos, P.S.; Sundefeld, M.L.; Biasoli, É.R.; Miyahara, G.I.; Soubhia, A.M.; de Andrade, M.; et al. Stress hormones concentrations in the normal microenvironment predict risk for chemically induced cancer in rats. Psychoneuroendocrinology 2018, 1, 229-238. [CrossRef] [PubMed]

32. McDonald, P.G.; O'Connell, M.; Lutgendorf, S.K. Psychoneuroimmunology and cancer: A decade of discovery, paradigm shifts, and methodological innovations. Brain Behav. Immun. 2013, 30, S1-S9. [CrossRef] [PubMed]

33. Deshmukh, S.K.; Srivastava, S.K.; Poosarla, T.; Dyess, D.L.; Holliday, N.P.; Singh, A.P.; Singh, S. Inflammation, immunosuppressive microenvironment and breast cancer: Opportunities for cancer prevention and therapy. Ann. Transl. Med. 2019, 7, 593. [CrossRef] [PubMed]

34. Manea, L.; Gilbody, S.; McMillan, D. Optimal cut-off score for diagnosing depression with the Patient Health Questionnaire (PHQ-9): A meta-analysis. Can. Med. Assoc. J. 2011, 184, E191-E196. [CrossRef] [PubMed]

35. Mills, S.D.; Fox, R.S.; Malcarne, V.L.; Roesch, S.; Champagne, B.R.; Sadler, G.R. The Psychometric Properties of the Generalized Anxiety Disorder-7 scale in Hispanic Americans with English or Spanish Language Preference. Cult. Divers. Ethn. Minor. Psychol. 2014, 20, 463-468. [CrossRef] [PubMed] 
36. Hooper, L.M.; Stockton, P.; Krupnick, J.L.; Green, B.L. Development, use, and psychometric properties of the Trauma History Questionnaire. J. Loss Trauma 2011, 16, 258-283. [CrossRef]

37. Roy, C.A.; Perry, J.C. Instruments for the assessment of childhood trauma in adults. J. Nerv. Ment. Dis. 2004, $192,343-351$. [CrossRef]

38. Our World 2021: Emerging Hope: National \& Regional Demographics. La Salle Academy. 2021. Available online: https: / / lasalle-academy.libguides.com/ourworldpoverty/demographics (accessed on 25 May 2021).

39. Lutgendorf, S.K.; Andersen, B.L. Biobehavioral approaches to cancer progression and survival: Mechanisms and interventions. Am. Psychol. 2015, 70, 186-197. [CrossRef] [PubMed]

40. Maass, S.W.M.C.; Roorda, C.; Berendsen, A.J.; Verhaak, P.F.M.; De Bock, G.H. The prevalence of long-term symptoms of depression and anxiety after breast cancer treatment: A systematic review. Maturitas 2015, 82, 100-108. [CrossRef]

41. Mersky, J.; Janczewski, C. Racial and ethnic differences in the prevalence of adverse childhood experiences: Findings from a low-income sample of U.S. women. Child Abuse Negl. 2017, 76, 480-487. [CrossRef]

42. Llabre, M.M.; Schneiderman, N.; Gallo, L.C.; Arguelles, W.; Daviglus, M.L.; Gonzalez, F. Childhood Trauma and Adult Risk Factors and Disease in Hispanics/Latinos in the US: Results From the Hispanic Community Health Study/Study of Latinos (HCHS/SOL) Sociocultural Ancillary Study. Psychosom. Med. 2017, 79, 172-180. [CrossRef]

43. Jiao-Mei, X.; Wen, G.; Feng-Lin, C. Quality of life among breast cancer survivors 2 years after diagnosis: The relationship with adverse childhood events and posttraumatic growth. Cancer Nurs. 2016, 39, E32-E39. [CrossRef]

44. Fagundes, C.; Lindgren, M.; Shapiro, C.; Kiecolt-Glaser, J. Child Maltreatment and Breast Cancer Survivors: Social Support Makes a Difference for Quality of Life, Fatigue, and Cancer Stress. Eur. J. Cancer 2011, 48, 728-736. [CrossRef] [PubMed]

45. Breiding, M.J.; Smith, S.G.; Basile, K.C.; Walters, M.L.; Chen, J.; Merrick, M.T. Prevalence and characteristics of sexual violence, stalking, and intimate partner violence victimization-National Intimate Partner and Sexual Violence Survey, United States, 2011 Am. J. Public Health 2015, 105, e11-e12.

46. Cuevas, C.A.; Sabina, C.; Milloshi, R. Interpersonal victimization among a national sample of Latino women. Violence Against Women 2012, 18, 377-403. [CrossRef]

47. Dey, A.; Hankey Giblin, P.A. Insights into Macrophage Heterogeneity and Cytokine-Induced Neuroinflammation in Major Depressive Disorder. Pharmaceuticals 2018, 11, 64. [CrossRef] [PubMed]

48. Man, Y.G.; Stojadinovic, A.; Mason, J.; Avital, I.; Bilchik, A.; Bruecher, B.; Jewett, A.; Protic, M.; Nissan, A.; Izadjoo, M.; et al. Tumor-infiltrating immune cells promoting tumor invasion and metastasis: Existing theories. J. Cancer 2013, 4, 84-95. [CrossRef]

49. Dushyanthen, S.; Beavis, P.A.; Savas, P.; Teo, Z.L.; Zhou, C.; Mansour, M.; Loi, S.; Darcy, P.K. Relevance of tumor-infiltrating lymphocytes in breast cancer. BMC Med. 2015, 13, 202. [CrossRef]

50. Ali, H.R.; Chlon, L.; Pharoah, P.D.P.; Markowetz, F.; Caldas, C. Patterns of Immune Infiltration in Breast Cancer and Their Clinical Implications: A Gene-Expression-Based Retrospective Study. PLoS Med. 2016, 13, e1002194. [CrossRef]

51. Gu, Y.; Liu, Y.; Fu, L.; Zhai, L.; Zhu, J.; Han, Y.; Cao, X.; Zhang, Y.; Zhang, P.; Jiang, Z.; et al. Tumor-educated B cells selectively promote breast cancer lymph node metastasis by HSPA4-targeting IgG. Nat. Med. 2019, 25, 312-322. [CrossRef]

52. Ishigami, E.; Sakakibara, M.; Sakakibara, J.; Masuda, T.; Fujimoto, H.; Hayama, S.; Otsuka, M. Coexistence of regulatory B cells and regulatory $\mathrm{T}$ cells in tumor-infiltrating lymphocyte aggregates is a prognostic factor in patients with breast cancer. Breast Cancer 2019, 26, 180-189. [CrossRef] [PubMed]

53. Danese, A.; Baldwin, J. Hidden Wounds? Inflammatory Links Between Childhood Trauma and Psychopathology. Annu. Rev. Psychol. 2017, 68, 517-544. [CrossRef] [PubMed]

54. Danese, A.; Pariante, C.M.; Caspi, A.; Taylor, A.; Poulton, R. Childhood maltreatment predicts adult inflammation in a life-course study. Proc. Natl. Acad. Sci. USA 2015, 104, 679-693. [CrossRef] [PubMed]

55. Harris, L.N.; Bauer, M.R.; Wiley, J.F.; Hammen, C.; Krull, J.L.; Crespi, C.M.; Stanton, A.L. Chronic and episodic stress predict physical symptom bother following breast cancer diagnosis. J. Behav. Med. 2017, 40, 875-885. [CrossRef] [PubMed] 